\title{
Contaminação provocada por um depósito de lixo no aquiúfero Alter do Chão em Manaus - AM
}

\author{
Luiz Cláudio Ribeiro da ROCHA ${ }^{1} \&$ Adriana Maria Coimbra HORBE ${ }^{2}$
}

\begin{abstract}
RESUMO
Este trabalho discute a composição química da água do aqüífero Alter do Chão na área do entorno de um lixão na cidade de Manaus. Foram analisados $\mathrm{pH}$, Eh, turbidez, nitrato, nitrito, amônia e os elementos $\mathrm{Cl}$, F, Si, K, Na, Ca, Mg, Al, As, Mn, P, Sb, Ba, Cr, Fe, Se, $\mathrm{Sn}, \mathrm{Cd}, \mathrm{Cu}, \mathrm{Pb}$ e Zn, em dois períodos, no final do período chuvoso e na estiagem, em 18 poços e cacimbas. De acordo com os resultados obtidos, a água está comprometida para consumo humano na quase totalidade dos poços amostrados, em consequiência dos elevados teores de Al, $\mathrm{Fe}, \mathrm{As}$, $\mathrm{Cd}, \mathrm{Pb}, \mathrm{Sb}$ e Se, dos compostos nitrogenados e também por contaminaçóes pontuais de $\mathrm{Mn}$ e $\mathrm{Zn}$. A pluma de contaminação, que se expande no final do período chuvoso, estende-se para leste e sudeste do lixão, em função das direçôes naturais de fluxo do aqüífero e do baixo potenciométrico gerado pelo igarapé que corta a área.
\end{abstract}

PALAVRAS-CHAVE

Á gua subterrânea, contaminação, elementos metálicos, potabilidade, aqüífero Alter do Chão.

\section{Contamination provoked by a garbage dump in the Alter do Chão aquifer in Manaus-AM}

\section{ABSTRACT}

The present paper deals with the chemical composition of water from deep and shallow wells and water-holes near a garbage dump in the city of Manau. $p H$, Eh, turbidity, nitrate, nitrite, ammonia and the elements $\mathrm{Cl}, \mathrm{F}, \mathrm{Si}, \mathrm{K}, \mathrm{Na}, \mathrm{Ca}, \mathrm{Mg}, \mathrm{Al}, \mathrm{As}, \mathrm{Mn}, \mathrm{P}, \mathrm{Sb}, \mathrm{Ba}, \mathrm{Cr}, \mathrm{Fe}, \mathrm{Se}$, $\mathrm{Sn}, \mathrm{Cd}, \mathrm{Cu}, \mathrm{Pb}$ and $\mathrm{Zn}$ were analysed at the end of the rainy season and in the dry period in 18 wells. In almost all wells the water is no longer suitable for human consumption due the high contents of $\mathrm{Al}, \mathrm{Fe}, \mathrm{As}, \mathrm{Cd}, \mathrm{Pb}$, Sb and Se, nitrogen compounds and local contaminations by $M n$ and $Z n$. The contamination plume, which expands at the end of the rainy season, extends to the east and southeast of the garbage dump on account of the natural directions of the aquifer flow and the potenciometric low level generated by the stream flow cutting through the area.

\section{KEY WORDS}

Underground water, contamination, metallic elements, drinkable water, aquifer Alter do Chão.

\footnotetext{
${ }^{1}$ Curso de pós-graduação, Departamento de Geociências, Universidade Federal do Amazonas

${ }^{2}$ Departamento de Geociências, Universidade Federal do Amazonas - Av. Gal. Rodrigo 0. J. Ramos 3000, Japiim, 69077-000, Manaus -AM ahorbe@ufam.edu.br;
} 


\section{INTRODUÇÃO}

A falta de critérios ambientais na instalação de lixões tem provocado, ao longo do tempo, inúmeros problemas de contaminação de solos e recursos hídricos (Sissino \& Moreira, 1996, Barbosa \& Otero, 1999, Abu-Rukah \& Al-Kofahi, 2001, entre outros) que tem afetado, especialmente a população de baixa renda com saneamento básico deficiente. Na década de 70 foi destinada uma área na periferia de Manaus para deposição de lixo e quinze anos depois o local foi aterrado. Parte da área foi ocupada por famílias de baixa renda que formaram o bairro de Novo Israel e, conseqüentemente, foram perfuradas cacimbas e poços para o abastecimento de água. Atualmente, a área está urbanizada, contudo restos do antigo lixão estão expostos e o igarapé que corta a área está contaminado por aportes de lixos, esgoto e água servida. Essa situação tem agravado a saúde da população local de modo que os casos de hanseníase, doenças de pele e câncer são mais elevados que nos demais bairros da cidade (Stork, 2003 comunicação pessoal).

Com o objetivo de determinar o impacto e a extensão da pluma de contaminação resultante da decomposição e infiltração do chorume proveniente do lixo acumulado sobre o aqüífero Alter do Chão, foram selecionados 18 pontos, entre cacimbas e poços, alguns com até $80 \mathrm{~m}$ de profundidade, para estudos da qualidade da água utilizada pela população. A área de estudo cobre a zona do lixão propriamente dito e o seu entorno (Fig. 1).

\section{CARACTERÍSTICAS DA ÁGUA DO AQÜÍFERO DE MANAUS}

A água subterrânea da regiáo de Manaus, relacionada ao aqüífero da Formação Alter do Chão, apresenta temperatura média entre $27^{\circ} \mathrm{C}$ e $29^{\circ} \mathrm{C}$, é levemente redutora (Eh entre 93

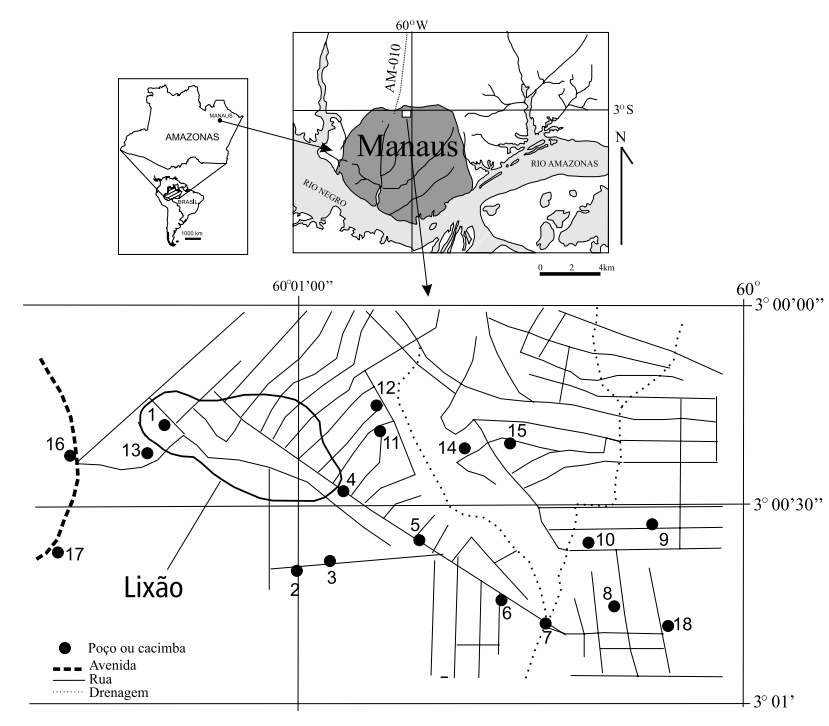

Figura 1 - Mapa de localização e dos pontos analisados
mV e 256 mV) e ácida (pH entre 2,6 e 5,9) (Silva 1999, 2001 e Cunha \& Rocha Neto 2001). Varia entre potássica e sódica, é fracamente mineralizada, tem condutividade elétrica entre 11,10 $i \mathrm{~S} / \mathrm{cm}$ e $87,9 \mathrm{i} S / \mathrm{cm}$, com significativa correlação entre esse parâmetro e $\mathrm{Mg}^{2+}, \mathrm{Ca}^{2+}, \mathrm{HCO}_{3}^{-}, \mathrm{K}^{+}$e, conseqüentemente, com a dureza (Silva 1999).

O cloro, com até $3 \mathrm{mg} \mathrm{L}^{-1}$, éo ânion principal, mas localmente pode predominar o bicarbonato. Amônia e nitrato são baixos $\left(0,04 \mathrm{mg} \mathrm{L}^{-1}\right.$ e $\left.0,17 \mathrm{mg} \mathrm{L}^{-1}\right)$, assim como o ferro $\left(\mathrm{Fe}^{3+}\right)$ e o ferro ferroso $\left(\mathrm{Fe}^{2+}\right)$ com teores variando de $0,005 \mathrm{mg} \mathrm{L}^{-1}$ a $0,441 \mathrm{mg}$ $\mathrm{L}^{-1}$ e o ferro total entre $0,005 \mathrm{mg} \mathrm{L}^{-1}$ e $0,959 \mathrm{mg} \mathrm{L}^{-1}$ (Silva, 1999). Essas características determinam a boa qualidade da água do aquífero de Manaus, apesar do baixo conteúdo de álcalis o que a torna mais ácida, provavelmente em consequiência de percolarem arenitos cauliníticos de médios a grossos e conglomerados de quartzo com predominância de silício e alumínio.

\section{MATERIAIS E MÉTODOS}

Foi estudada a água de 18 locais, dos quais 5 de cacimbas com até $6 \mathrm{~m}, 7$ poços entre $11 \mathrm{e} 35 \mathrm{~m}$ de profundidade, $1 \mathrm{com}$ $66 \mathrm{~m}$ e cinco com $80 \mathrm{~m}$ (Tab. 1). Os poços mais rasos e de custo menor concentram-se na porção leste, mais baixa topograficamente, enquanto os mais profundos estão na zona mais elevada, mas diretamente sobre do lixão ou a leste deste (Fig. 1). As coletas ocorreram em junho de 2002, aproveitando o final da época das chuvas, e em dezembro do mesmo ano quando a região apresenta clima mais seco. Foram utilizadas garrafas de polietileno, lavadas em solução de ácido nítrico a $20 \%$ e água deionizada. No local de amostragem, os recipientes foram lavados três vezes com a água do ponto selecionado, antes da amostragem final. Nos poços com bomba a amostra foi coletada diretamente na saída desta após alguns instantes da água começar a vazar.

Foram analisados $\mathrm{pHe}$ eh, no local da amostragem, e turbidez com a água in natura no laboratório. Para as demais informaçôes químicas (nitrato, nitrito, amônia, $\mathrm{Cl}, \mathrm{Si}, \mathrm{K}, \mathrm{Na}, \mathrm{Ca}, \mathrm{Mg}, \mathrm{Al}, \mathrm{As}$, $\mathrm{Mn}, \mathrm{P}, \mathrm{Sb}, \mathrm{Ba}, \mathrm{Cr}, \mathrm{Fe}, \mathrm{Se}, \mathrm{Sn}, \mathrm{Cd}, \mathrm{Cu}, \mathrm{Pb}$ e Zn), a amostra foi filtrada em fibra de vidro de 0,45 ìm e conservada com adição de $\mathrm{HNO}_{3}$ puro bi-destilado. $\mathrm{O}$ nitrato, nitrito, amônia, $\mathrm{Cl}$, foram analisados nessa condição, enquanto para os outros elementos as amostras foram concentradas quatro vezes (volume reduzido de $400 \mathrm{ml}$ para $100 \mathrm{ml}$ ). Os métodos empregados foram turbidimetria (turbidez), potenciometria ( $\mathrm{pH} \mathrm{eEh),} \mathrm{FIA} \mathrm{(nitrato,}$ nitrito e amônia), volumetria $(\mathrm{Cl})$, colorimetria $\left(\mathrm{SiO}_{2}\right)$ e por espectrometria de indução acoplada ( $\mathrm{Na}, \mathrm{K}, \mathrm{Ca}, \mathrm{Mg}, \mathrm{Al}, \mathrm{Fe}, \mathrm{Cd}$, $\mathrm{Pb}, \mathrm{Sb}, \mathrm{Se}, \mathrm{As}, \mathrm{Zn}, \mathrm{Mn}, \mathrm{B}, \mathrm{Ba}, \mathrm{Cu}, \mathrm{Cr}$ e Ni). Arsênio e Se foram analisados somente no período de estiagem ( $2^{\mathrm{a}}$. campanha de amostragem). 
Tabela 1 - Composição química das águas subterrâneas do Bairro de Novo Israel (Manaus-AM).

\begin{tabular}{|c|c|c|c|c|c|c|c|c|c|}
\hline Poço & Característica & Prof.(m) & Latitude & Longitude & $\mathrm{pH}(1)$ & $\mathrm{pH}(2)$ & Eh(1) & Eh(2) & Turbidez (1) \\
\hline 01 & Poço & 80 & 831851 & 9664665 & 4,8 & 4,1 & 195 & 259 & 0,3 \\
\hline 02 & Cacimba & 1,80 & 832115 & 9664456 & 5,4 & 4,6 & 177 & 238 & 2,2 \\
\hline 03 & Poço & 80 & 832197 & 9664457 & 4,8 & 4,7 & 280 & 186 & 0,2 \\
\hline 04 & Poço & 80 & 832234 & 9664548 & 6,5 & 6,5 & 227 & 176 & 0,8 \\
\hline 05 & Poço & 30 & 832714 & 9664408 & 6,3 & 7,3 & 229 & 169 & 0,3 \\
\hline 06 & Poço & 24 & 832626 & 9664266 & 4,3 & 4,4 & 321 & 261 & 0,9 \\
\hline 07 & Cacimba & 2,5 & 832785 & 9964208 & 5,9 & 6,5 & 279 & 273 & 4,3 \\
\hline 08 & Poço & 15 & 832906 & 9664226 & 4,5 & 4,3 & 337 & 176 & 0,4 \\
\hline 09 & Poço & 11 & 833014 & 9664435 & 3,9 & 3,8 & 370 & 372 & 0,2 \\
\hline 10 & Poço & 6 & 832782 & 9664386 & 4,7 & 4,6 & 330 & 405 & 0,8 \\
\hline 11 & Poço & 18 & 832332 & 9664666 & 5,7 & 6,0 & 290 & 345 & 0,9 \\
\hline 12 & Cacimba & 5 & 832336 & 9664751 & 4,9 & 4,8 & 318 & 314 & 4,2 \\
\hline 13 & Poço & 66 & 831808 & 9664577 & 4,7 & 3,4 & 317 & 427 & 0,4 \\
\hline 14 & Cacimba & 3 & 832702 & 9664651 & 4,4 & 4,2 & 348 & 385 & 0,3 \\
\hline 15 & Poço & 20 & 832559 & 9664630 & 4,9 & 4,0 & 320 & 400 & 0,3 \\
\hline 16 & Poço & 80 & 831230 & 9664146 & 4,8 & 5,2 & 325 & 289 & 3,0 \\
\hline 17 & Poço & 80 & 830928 & 9664192 & 4,6 & 4,4 & 338 & 341 & 0,2 \\
\hline 18 & Poço & 35 & 832879 & 9664060 & 4,5 & 4,7 & 336 & 287 & 0,2 \\
\hline
\end{tabular}

Eh em mV e turbidez em UNT, (1)Valores obtidos na amostragem em junho/2002, (2)Valores obtidos na amostragem em dezembro/2002

CARACTERÍSTICAS FÍSICAS E QUIIMICAS DAS ÁGUAS DO AQÜÍFERO ALTER DO CHÃO EM NOVO ISRAEL

As águas do aquiífero na área estudada são ácidas a neutras ( $\mathrm{pH}$ entre 3,8 e 6,5) e oxidantes (Eh entre 195 e $405 \mathrm{mV}$ ) sem variação significativa entre os dois períodos analisados, entretanto mais oxidantes e um pouco mais alcalinas que as de Silva (1999). São águas límpidas exceto as das cacimbas que apresentam turbidez de até 4,3 FTU (Tab. 1).

Nos pontos estudados o $\mathrm{NH}_{4}^{+}$supera o teor médio de Silva (1999) $\left(0,04 \mathrm{mg} \mathrm{L}^{-1}\right)$ alcança $13,45 \mathrm{mg} \mathrm{L}^{-1} \mathrm{em} \mathrm{dez} \mathrm{poços} \mathrm{no}$ final do período chuvoso e em 13 na estiagem, enquanto $\mathrm{NO}_{3}^{-}$ , com até $17,8 \mathrm{mg} \mathrm{L}^{-1}$ é superior aos desse autor $\left(0,17 \mathrm{mg} \mathrm{L}^{-1}\right)$ em todos os pontos nas duas estaçôes climáticas (Fig. 2). Em quatro dos pontos analisados o teor de $\mathrm{NH}_{4}^{+}$, e em cinco o de $\mathrm{NO}_{3}^{-}$, são maiores que o máximo permitido pela legislação ambiental (1,5 mg L-1 e $10 \mathrm{mg} \mathrm{L}^{-1}$, respectivamente) essa situação se agrava na estiagem com o aumento no teor desses compostos atingindo até $16,14 \mathrm{mg} \mathrm{L}^{-1}$ e $30,7 \mathrm{mg} \mathrm{L}^{-1}$, respectivamente (Fig. 2). Os teores elevados desses íons estão tanto nas cacimbas como nos poços com $80 \mathrm{~m}$. O NO ${ }_{2}^{-}$é menor que $0,085 \mathrm{mg} \mathrm{L}^{-1} \mathrm{em}$ todos os pontos analisados, portanto não oferece risco a saúde.

$\mathrm{O} \mathrm{Cl}^{-}$é o elemento mais abundante dentre os íons analisados, predomina na estiagem atingindo teores máximos de $54 \mathrm{mg} \mathrm{L}^{-1}$. Por ser altamente solúvel e conservativo, é utilizado como traçador de contaminação de lixões (Barbosa \& Otero, 1999). Assim, por não ocorrer nos arenitos da Formação Alter do Chão, pode-se considerar que somente valores de $\mathrm{Cl}^{-}$acima de $3 \mathrm{mg} \mathrm{L}^{-1}$, que representa o teor mais alto encontrado por Silva (1999) no aquííero de Manaus não associado a contaminação, são indicativos de alteração química da água. Desse modo somente os poços 1 , 5, 6, 13 e 16 no final do período chuvoso não têm indícios de influência do lixão apesar do ponto 1 estar sobre este (Fig. 2). $\mathrm{Na}$ estiagem a contaminação se expande e atinge todos os poços exceto os 13 e 16. $\mathrm{Na}$ relação $\mathrm{Cl}^{-}-\mathrm{NH}_{4}{ }^{+}-\mathrm{NO}_{3}{ }^{-}$nota-se que tanto a água de Novo Israel como a do restante do aqüífero (Silva 1999) é predominantemente clorada, mas a influência do lixão aumenta a proporção de nitrato, especialmente no final do período chuvoso (Fig 3A).

$\mathrm{O}$ segundo elemento mais abundante é o $\mathrm{Na}^{+}$, atinge o máximo de 45,8 $\mathrm{mg} \mathrm{L}^{-1}$ no final do período chuvoso e é superado pelo $\mathrm{K}^{+}$, analisado apenas na estiagem nos pontos 4 e 5 onde alcança $48 \mathrm{mg} \mathrm{L}^{-1}$ (Fig. 2). $\mathrm{O} \mathrm{Ca}^{2+} \mathrm{e} \mathrm{Mg}^{2+}$ têm teores mais baixos, entre 0,05 e $35,8 \mathrm{mg} \mathrm{L}^{-1}$ e entre $<0,01$ e 7,98 $\mathrm{mg} \mathrm{L}^{-1}$ respectivamente, o primeiro predomina no período chuvoso e o segundo na estiagem (Fig. 2). Os pontos com teores mais altos desses dois elementos (P4 e P5) coincidem com os de $\mathrm{K}^{+}$mais elevados (Fig.2). Dentre esses elementos, o $\mathrm{Na}^{+}$é o que apresenta teores mais elevados em relação aos de Silva (1999), entre 0,5 e $4,5 \mathrm{mg} \mathrm{L}^{-1}$, enquanto $\mathrm{K}^{+}\left(0,1\right.$ e $\left.13,4 \mathrm{mg} \mathrm{L}^{-1}\right), \mathrm{Ca}^{2+}(0,001 \mathrm{e}$ $\left.5,45 \mathrm{mg} \mathrm{L}^{-1}\right)$ e $\mathrm{Mg}^{2+}\left(0,02\right.$ e 2,82 $\left.\mathrm{mg} \mathrm{L}^{-1}\right)$ são maiores em um número menor de poços. Não há relação entre o teor desses elementos e a profundidade dos pontos analisados, pois tanto a água das cacimbas como a dos poços mais profundos está alterada quimicamente em relação aos dados de Silva (1999). 

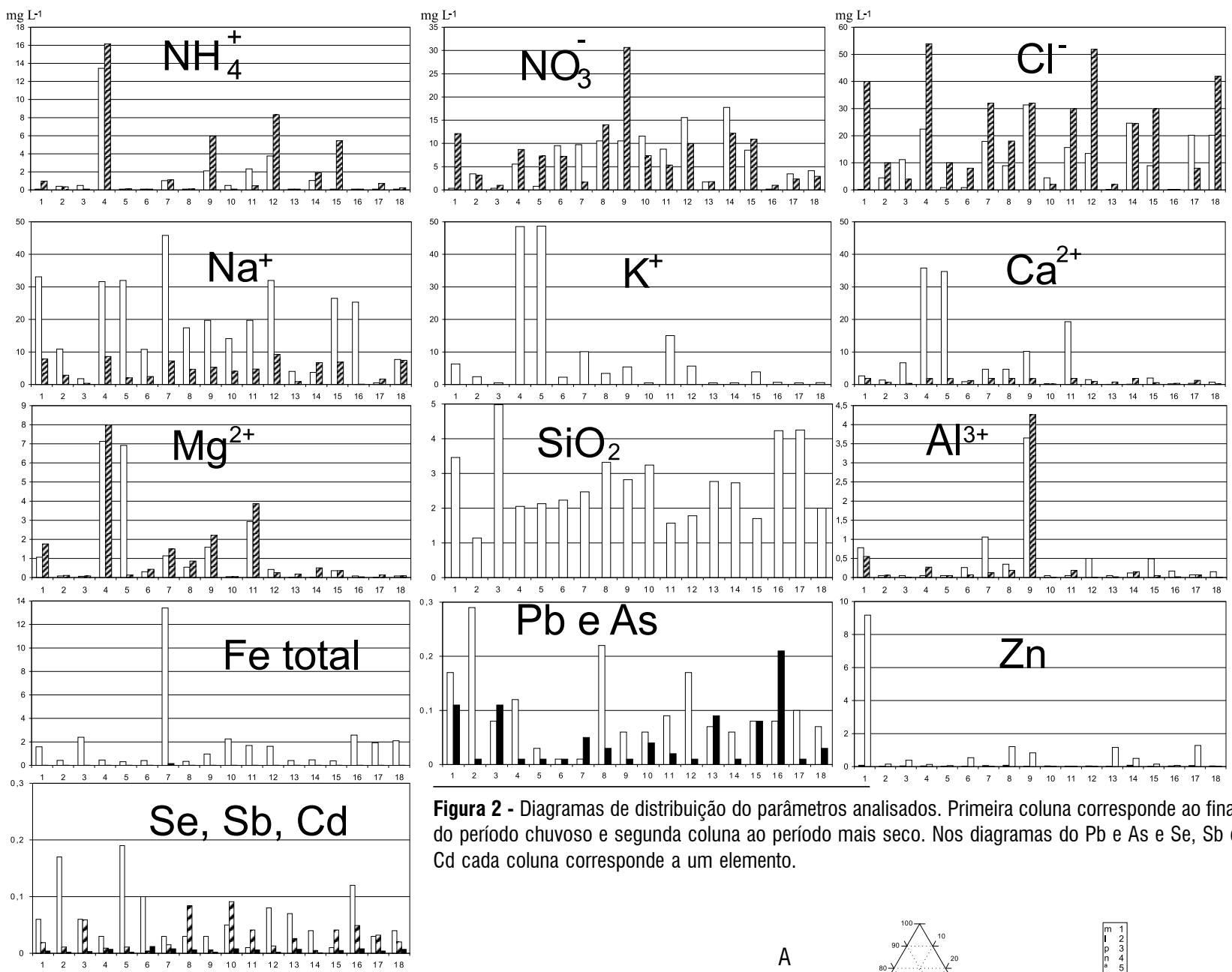

Figura 2 - Diagramas de distribuição do parâmetros analisados. Primeira coluna corresponde ao final do período chuvoso e segunda coluna ao período mais seco. Nos diagramas do Pb e As e Se, Sb e $\mathrm{Cd}$ cada coluna corresponde a um elemento.

Considerando a relação desses cátions constata-se que a influência do $\mathrm{Na}$ é mais acentuada que nas não contaminadas de Silva (1999), especialmente no final do período chuvoso (Fig. 3B).

$\mathrm{O} \mathrm{SiO}_{2}$, analisado somente no final do período chuvoso, apresenta teores entre 1,14 e 4,98 $\mathrm{mg} \mathrm{L}^{-1}$. Não há informaçōes de teores desse elemento no aqüífero de Manaus, mas são mais baixos que os das águas pretas da região (Santos et al. 1984). O $\mathrm{Al}^{3+}$ tem pouca variação entre os dois períodos, mas cinco poços, com teores entre 0,49 e $3,65 \mathrm{mg} \mathrm{L}^{-1}$ no final do período chuvoso e em três, com 0,27 a 4,26 mg L-1 na estiagem, estão acima do máximo permitido $\left(0,2 \mathrm{mg} \mathrm{L}^{-1}\right)$ pela legislação ambiental (Fig. 2). O Fe total também está acima do máximo permitido $(0,03$ $\left.\mathrm{mg} \mathrm{L}^{-1}\right)$ na época chuvosa, entre 0,34 e $13,4 \mathrm{mg} \mathrm{L}^{-1}$ e em relação aos de Silva (1999) $\left(0,01 \mathrm{mg} \mathrm{L}^{-1}\right)$, mas difere dos demais elementos analisados nas duas campanhas, pois é o único que decresce em todos os pontos para a estiagem (Fig. 2).

Dentre os elementos-traço analisados, $\mathrm{B}, \mathrm{Cd}, \mathrm{Pb}, \mathrm{Sb}, \mathrm{Cr}, \mathrm{Ni}$, $\mathrm{Ba}, \mathrm{Cu}$ e Zn estão abaixo ou próximos do limite de detecção no período chuvoso, não apresentam concentraçôes perigosas para
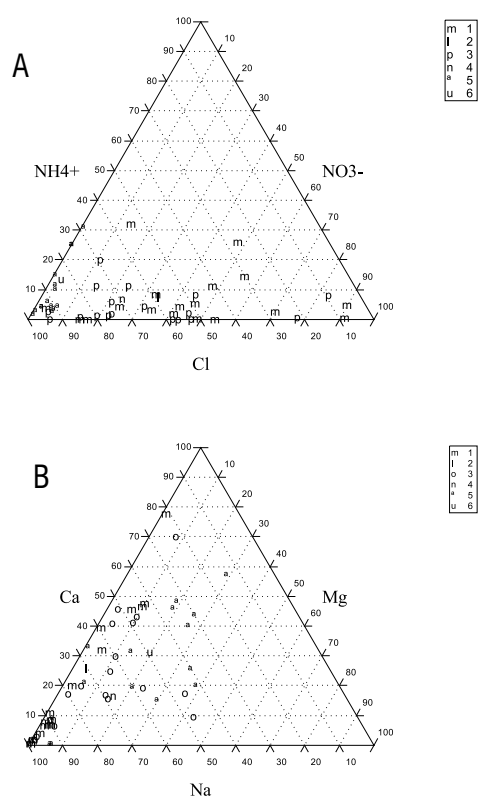

Figura 3 - Relação entre os principais ânions $\left(\mathrm{Cl}^{-}, \mathrm{NH}_{4}{ }^{+}\right.$e $\left.\mathrm{NO}_{3}{ }^{-}\right)$e cátions $\left(\mathrm{Na}^{+}, \mathrm{Ca}^{2+} \mathrm{e} \mathrm{Mg}^{2+}\right)$ na água do aqǘfero Alter do Chão em Novo Israel. 1- no final do período chuvoso, 2-média desse período, 3-período seco, 4- média desse período, 5- dados de Silva (1999), 6-média desse autor. 
seres humanos e, assim como o $\mathrm{SiO}_{2}$, estes e os demais elementostraço (Mn, Se e As) não foram analisados por outros autores no aqǘfero de Manaus. O Mn também está abaixo do máximo permitido nos dois períodos analisados, mas tem leve aumento no ponto $7 \mathrm{no}$ final da época das chuvas $\left(0,12 \mathrm{mg} \mathrm{L}^{-1}\right)$. O B, analisado somente no final das chuvas, têm teores baixos, inferiores a $0,09 \mathrm{mg} \mathrm{L}^{-1}$, exceto no ponto 11 onde alcança $0,14 \mathrm{mg} \mathrm{L}^{-1}$. Na segunda campanha, Cr e Ni também estão abaixo ou próximos do limite de detecção $\left(0,01 \mathrm{mg} \mathrm{L}^{-1}\right)$, o Ba diminui de concentração nesse período exceto o P17 onde alcança $0,18 \mathrm{mg} \mathrm{L}^{-1} \mathrm{e} \mathrm{Cu}$ aumenta em sete poços analisados atingindo $0,40 \mathrm{mg} \mathrm{L}^{-1}$ no P9. $\mathrm{O} Z n$ também aumenta de teor na estiagem, mas está acima do máximo permitido ( $\left.5 \mathrm{mg} \mathrm{L}^{-1}\right)$ somente no poço 1 (Fig. 2).

$\mathrm{O} \mathrm{Pb}, \mathrm{Sb}$ e Cd na estiagem e As, $\mathrm{Se}$, analisados somente nesse período, têm teores acima do máximo permitido na maioria dos poços analisados (Fig.2). O Pb atinge o máximo de $0,29 \mathrm{mg} \mathrm{L}^{-}$ ${ }^{1}$, As $0,21 \mathrm{mg} \mathrm{L}^{-1}$, Se $0,19 \mathrm{mg} \mathrm{L}^{-1}$, Sb 0,084mg L-1 e Cd 0,012 $\mathrm{mg} \mathrm{L} \mathrm{L}^{-1}$.

\section{A PLUMA DE CONTAMINAÇÃO}

È indiscutível que a água subterrânea do aqüífero Alter do Chão em Novo Israel está modificada física e quimicamente em relação ao restante da região, o que permite atribuir esse fato ao lixo depositado sem nenhum controle. Devido a malha de poços ter sido feita para atender a população, que está concentrada em uma faixa leste-oeste a partir do lixão, ela tem má distribuição areal e profundidades muito variáveis para um estudo visando a delimitação da pluma de contaminação. Contudo, considerandose o $\mathrm{Cl}^{-}$, que é conservativo e altamente móvel, nos poços entre $1,5 \mathrm{~m}$ e $15 \mathrm{~m}$ de profundidade e nos de $18 \mathrm{~m}$ a $66 \mathrm{~m}$ nota-se que a pluma estende-se para leste-sudeste (Fig 4). Nos poços com 80 $\mathrm{m}$, mais próximos ao aterro a pluma está circunscrita a este no período mais seco, mas desloca-se para sul no final do chuvoso. Essas informaçôes, apesar de restritas, permitem presumir que a pluma de contaminação se estende para além dos limites estudados, especialmente para $\mathrm{SE}$, provavelmente influenciada pelo baixo potenciométrico identificado por CPRM (2002) na área, provocado pelo igarapé Novo Israel que faz com que a água subterrânea migre ao longo do seu canal. Contudo, os poços P9 e P18, localizados a leste e na margem esquerda da drenagem, e o P17, a oeste do lixão (Fig. 1), todos com teores elevados de $\mathrm{Cl}^{-}$ , deveriam estar fora de sua área de influência, considerando-se esse baixo potenciométrico. Isso permite inferir que parte da contaminação constatada nesses poços pode estar relacionada à ocupação atual da área ou a variaçôes nas características hidráulicas e na idade do lixão que, conforme observado por Barbosa \& Otero (1999), podem interferir no fluxo normal de uma pluma.

A contaminação dos poços profundos com $\mathrm{Cl}^{-}$, especialmente em P1 e P4, ambos com $80 \mathrm{~m}$, com teores acima de $40 \mathrm{mg} \mathrm{L}^{-1}$ na estiagem, demonstra que não há atenuação da contaminação desse íon com o aumento da profundidade por adsorção e troca

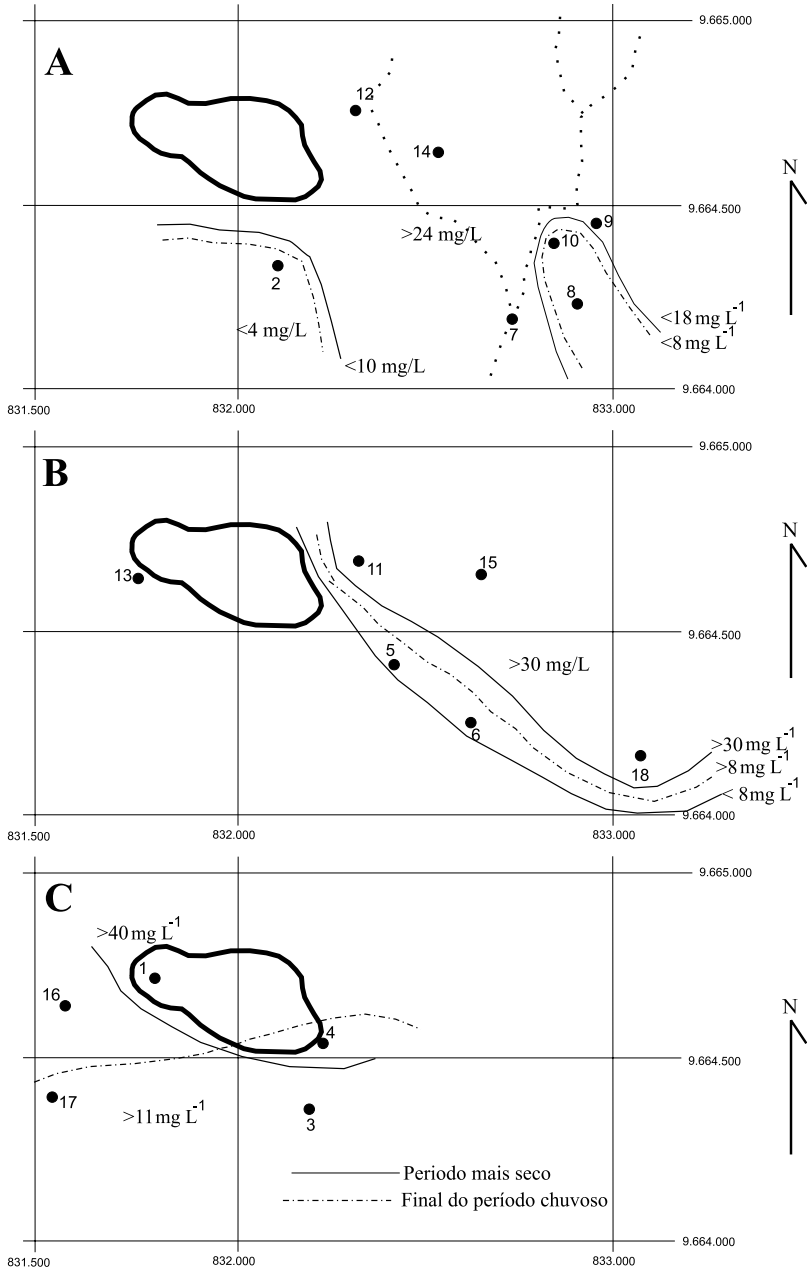

Figura 4 - Mapa de distribuição do $\mathrm{Cl}$ na área estudada. A- poços entre 1,5 e $15 \mathrm{~m}, \mathrm{~B}$ - poços entre 18 e $66 \mathrm{~m}, \mathrm{C}$ - poços com $80 \mathrm{~m}$. Profundidade dos poços ver figura 2 .

iônica com os minerais dos sedimentos percolados, como pode ocorrer em ambientes similares segundo Peters (1993). Também não se observa atenuação nos metais apesar de serem mais facilmente adsovidos que o $\mathrm{Cl}^{-}$na estrutura dos minerais (Peters 1993; Sissino \& Moreira, 1996 e Feitosa \& Manoel Filho 1997), pois $\mathrm{Fe}^{3+}, \mathrm{Cd}, \mathrm{As}, \mathrm{Sb}, \mathrm{Pb}$ e Se têm os teores elevados em quase todos os poços inclusive no 16 não afetado pelo $\mathrm{Cl}$. Entretanto, $\mathrm{NO}_{3}^{-}, \mathrm{NH}_{4}^{+} \mathrm{e} \mathrm{Al}^{3+}$ podem estar sendo retardados, pois os teores acima do máximo permitido estão mais próximos ao lixão, exceto o P9 na margem esquerda do igarapé Novo Israel (Fig. 1).

Fatores como irregularidades de permeabilidade do substrato, variações na composição mineralógica e na taxa de precipitação pluviométrica (Barbosa \& Otero, 1999) afetam a pluma de contaminação e podem modificar a dispersão natural dos elementos e, conseqüentemente, a atenuação. Todos esses fatores devem estar atuando no aqüífero estudado, pois os sedimentos 
da Formação Alter do Chão são constituídos por lentes argilosas em um pacote de arenito médio a fino, ambos de coloração avermelhada devido a presença de óxi-hidróxidos de ferro, o que coloca em contato porções cauliníticas com quartzosas de diferentes permeabilidades e capacidade de sorção. Além desses fatores que afetam a mobilidade dos elementos nas águas, a hidrodinâmica natural e, possivelmente a explotação atual do aqüífero, são fatores responsáveis pelo espalhamento dos contaminantes produzidos pelo lixão. Contudo, não se excluem problemas de má construção e conservação dos poços como outros fatores que podem estar influenciando a composição das águas.

\section{CONCLUSÃO}

Os dados apresentados mostram que a água subterrânea do bairro de Novo Israel está comprometida para consumo humano em conseqüência dos elevados teores de $\mathrm{Al}^{3+}, \mathrm{Fe}^{3+}, \mathrm{As}, \mathrm{Cd}, \mathrm{Pb}$, $\mathrm{Sb}$ e $\mathrm{Se}$, dos compostos nitrogenados e de contaminaçôes pontuais de Mn e Zn. A pluma de contaminação, que tende a se expandir na estiagem, estende-se para leste e sudeste ao longo do canal do igarapé Novo Israel, que age como baixo potenciométrico.

Devido a falta de maiores informaçoes, principalmente sobre a hidrodinâmica do aqüífero e do posicionamento dos filtros dos poços cadastrados, que permitam uma avaliação mais representativa sobre a forma e dimensôes da pluma de contaminantes, são necessários estudos complementares, inclusive nos bairros vizinhos, para determinar a real contribuição do lixão na contaminação da água subterrânea do bairro de Novo Israel e a possibilidade de aportes atuais.

\section{AGRADECIMENTOS}

Ao curso de pós-graduação em Geociências da UFAM pelo apoio logístico e financeiro e ao Geol. Carlos Aguiar da CPRMMA por sugestóes.

\section{BIBLIGRAFIA CITADA}

Abu-Rukah, Y.; Al-Kofahi, O. 2001. The assessment of the effect of landfill leachate on groundwater quality - a case study. ElAkader landfill site - north Jordan. Journal of Arid Environments, 49:615-630.

Cunha, H. B.; Rocha Neto, J.R. 2001. Avaliação fisico-química e biológica de poços rasos "cacimbas" da região leste da cidade de Manaus. X Jornada de Iniciação Científica do PIBIC/INPA. Manaus. 398-399pp.

Barbosa, R.M.; Otero O.M.F. 1999. Caracterização da pluma de poluição originada por depósito de lixo urbano. Geoquímica Brasiliensis, 13:51-65.

CPRM, 2002. Mapa hidrogeológico de Manaus. Companhia de pesquisa e recursos minerais - Serviço Geológico do Brasil. Relatório interno. $145 \mathrm{pp}$.

Feitosa, F.A.C.; Manoel Filho, J. 1997. Hidrologia, conceitos e aplicações. LABHID-UFPE, CPRM. 412p.

Peters, T. 1993. Chemical and physical changes in the subsoil of three waste landfills. Waste Management \& Research, 11:17-25.

Santos U. M.; Bringel S. R. B.; Bergamin F. H.; Ribeiro M. N. G.; Bananeira M. 1984. Rios da Bacia Amazônica I - Afluentes do Rio Negro. Acta Amazonica, 14: 222-237.

Silva, M.L. 2001. Características das águas subterrâneas numa faixa norte-sul na cidade de Manaus (AM). Revista da Escola de Minas, 54:115-120.

Silva, M.L. 1999. Hidroquímica elementar e dos isótopos de urânio nos aqüiferos de Manaus - AM. Master's Thesis, Universidade de São Paulo, Rio Claro, São Paulo. 135pp.

Sissino, C.L.S.; Moreira, J.C. 1996. Avaliação da contaminação e poluição ambiental na área de influência do aterro controlado do Morro do Céu, Niterói, Brasil. Cadernos de Saúde Pública, 12:515-523.

Recebido em 10/05/2005

Aceito em 15/08/2006 